\title{
Carrageenan Based Bionanocomposites as Drug Delivery Tool with Special Emphasis on the Influence of Ferromagnetic Nanoparticles
}

\author{
Abida Kalsoom Khan, ${ }^{1}$ Ain Us Saba, ${ }^{1}$ Shamyla Nawazish, ${ }^{2}$ Fahad Akhtar, ${ }^{3}$ \\ Rehana Rashid, ${ }^{1}$ Sadullah Mir, ${ }^{1}$ Bushra Nasir, ${ }^{4}$ Furqan Iqbal, ${ }^{4}$ Samina Afzal, ${ }^{4}$ \\ Fahad Pervaiz, ${ }^{5}$ and Ghulam Murtaza ${ }^{6,7}$ \\ ${ }^{1}$ Department of Chemistry, COMSATS Institute of Information Technology, Abbottabad 22060, Pakistan \\ ${ }^{2}$ Department of Environment Sciences, COMSATS Institute of Information Technology, Abbottabad 22060, Pakistan \\ ${ }^{3}$ Department of Biochemistry, Hazara University, Mansehra 21300, Pakistan \\ ${ }^{4}$ Faculty of Pharmacy, Bahauddin University, Multan, Pakistan \\ ${ }^{5}$ Faculty of Pharmacy and Alternative Medicines, Islamia University of Bahawalpur, Bahawalpur, Pakistan \\ ${ }^{6}$ Department of Pharmacy, COMSATS Institute of Information Technology, Abbottabad 22060, Pakistan \\ ${ }^{7}$ Institute of Automation, Chinese Academy of Sciences, Beijing 100190, China
}

Correspondence should be addressed to Abida Kalsoom Khan; abidak@ciit.net.pk

Received 5 August 2016; Revised 29 September 2016; Accepted 10 October 2016; Published 20 February 2017

Academic Editor: Janusz Gebicki

Copyright (C) 2017 Abida Kalsoom Khan et al. This is an open access article distributed under the Creative Commons Attribution License, which permits unrestricted use, distribution, and reproduction in any medium, provided the original work is properly cited.

Over the past few years, considerable attention has been focused on carrageenan based bionanocomposites due to their multifaceted properties like biodegradability, biocompatibility, and nontoxicity. Moreover, these composites can be tailored according to the desired purpose by using different nanofillers. The role of ferromagnetic nanoparticles in drug delivery is also discussed here in detail. Moreover, this article also presents a short review of recent research on the different types of the carrageenan based bionanocomposites and applications.

\section{Introduction}

In recent years, material chemists have fabricated advanced pharmaceuticals with improved biological, magnetic, and electrical characteristics. Nanoparticles have been studied as versatile drug delivery vehicles, particularly for targeted release of drug [1]. Accordingly, ferrous oxide nanoparticles (FENPs) possess excellent features such as superparamagnetism and low Curie temperature. Due to such characteristics, FONPs are extensively used as therapeutic tools, especially in cancer therapy [2]. Since FONPs are needed to be stabilized using suitable polymers [3], numerous studies on polysaccharide based magnetic nanocomposites have been reported [4].

Nanocomposites that contain naturally occurring polymers (biopolymer) in combination with an inorganic na- nomoiety represent a separate class of materials called bionanocomposites (BNCs). The term "bionanocomposite" also called "nanobiocomposites" (NCs), "green composites," or "biohybrids" was first used in 2004. Later on in 2011, there were about 66 articles in which this term was used $[5,6]$. BNCs form an interesting interdisciplinary area that combines material sciences, biology, and nanotechnology [7]. Due to nanometer sized particles that are thoroughly distributed in the polymer matrix, these BNCs show improved mechanical, gas barrier, and optical properties $[8,9]$. Moreover, BNCs exhibit significantly improved biodegradability and biocompatibility and also show functional properties that are being provided by biological or inorganic moieties [10]. BNCs are different from biocomposites that are partially made from biopolymers but they do not contain nanosize additives to inculcate the specific properties [7]. 
Biopolymers are the primary constituents for the synthesis of BNCs. These are classified as (i) polysaccharides, (ii) protein, (iii) DNA, and (iv) poly(hydroxyalkanoates); however polysaccharides and proteins are the most preferred groups.

1.1. Polysaccharides. Polysaccharides, also known as glycans, belong to carbohydrates. They can be obtained from various sources including seaweeds, plants, fungi, plants, insects, bacteria, crustacean, animals, and even humans [11]. They are subdivided into anionic and cationic polysaccharides. Carrageenan (CG) is a naturally occurring anionic sulphated polysaccharide extracted in 1837 from red seaweed of Rhodophyceae family, predominantly from Chondrus crispus, Eucheuma, Gigartina stellata, Iridaea, Hypnea, Solieria, Agardhiella, and Sarconema [12-14]. The word "carrageenan" is derived from Irish name "carrageen" meaning "little rock" [15]. It was first extracted by the people who lived in the vicinity of carrageen Ireland. Carrageenan is extracted by drying and washing seaweed in cool water. Seaweeds are then broken up and agitated in hot alkaline solution to extract CG. Once CG is in hot solution, it undergoes clarification and then is converted into powder [16].

Several methods have been used to remove CG from solution. First method is freeze thawing technique. In this method, solution is gelled with many salts and gels are frozen. Water is eliminated upon thawing and the resultant mass, that is, CG, and its salts are ground to the required particle size. Second technique is alcohol precipitation method. In this method, the concentrated solution of CG is placed in 2propanol or other alcohols, which cause the precipitation of solution. Solvent is then evaporated and precipitated CG is ground to fine particles. Third method is $\mathrm{KCl}$ precipitation process in which after hot extraction the filtrate is evaporated and then extruded through spinnerets into cold solution of $\mathrm{KCl}$. The resulting gel threads are then washed with $\mathrm{KCl}$ solution, pressed, dried, and milled to CG powder [17, 18]. Chondrus crispus, Gigartina stellata, Iridaea spp., Eucheuma spp., and Kappaphycus spp. are the prime raw materials used for CG extraction [16].

1.1.1. Summary of Carrageenan Types, Structure, and Properties. Carrageenan is found in several types in terms of chemical structure and properties, depending upon the species of seaweed used as a source. It is formed by alternate units of Dgalactose and 3,6-anhydrogalactose that are joined by $\alpha-1,3$ and $\beta-1,4$ glycosidic linkage. On the basis of type of bonding between galactose units and the position of attachment of sulphate groups to galactose unit, CG are categorized into $\lambda$ (lambda-) CG, $\kappa$ - (kappa-) CG, $\iota^{-}$(iota-) CG, $v$ - (nu-) CG, $\mu$ - (mu-) CG, $\theta$ - (theta-) CG, and $\xi$ - (Ksi-) CG, but on the basis of family, these are mainly of three types (Figure 1), $\iota$ CG, $\kappa$-CG, and $\lambda$-CG $[15,16,19,20]$. Among them, $\lambda$-CG has three sulphate groups per disaccharide repeating unit; $\kappa$-CG has one and $\iota$-CG has two sulphate groups per disaccharide repeating unit. So, they have different linear charge density $(\kappa<\iota<\lambda)$ [20] and solubility $(\kappa<\iota<\lambda)$ [21]. They differ in the presence of the 3,6-anhydrobridges and number of sulphate groups.
$\kappa$-CG is most abundant CG and Chondrus crispus constitutes $60 \%$ of CG. It is dissolved only in hot water and breaks down in acidic solution. Its structure shows that 3,6anhydrobridges are present in $\kappa$ - and $\iota$-CG but absent in $\lambda$ CG $[16,21] . \kappa-C G$ is insoluble in milk and salt solution while forming strong gels in potassium salt. $\lambda$-CG is second most abundant form of CG and is major constituent of Gigartina acicularis and Gigartina pistillata (Figure 2) [16]. It does not contain 3,6 anhydro-D-galactopyranosyl; thus it does not form gels and is used as a thickener [21]. ${ }_{-}$-CG is the least abundant and is found in Eucheuma spinosum. Gelling is the main property of $\kappa$ - and $\iota$-CG. $\kappa$-CG form brittle gels while $\iota$-CG form soft and elastic gels. It is considered that the presence of anhydrobridges is responsible for gelation. Gels formed by the CG are thermally reversible [22]. In $\kappa$ - and $\iota$-CG the adjacent spiral chains containing sulphate group towards external part cross-link to form a network of threedimensional double helix. Molecular weight of commercial CG ranges from 100 to $1000 \mathrm{kDa}[21,23]$.

Different properties of $\kappa^{-}, \iota^{-}$, and $\lambda$-CG make these polymers a versatile tool to develop useful biomaterials. Carrageenan is an exceptionally versatile material having wide range of applications in food and other industries. Food applications of CG are due to its gelling, thickening, emulsifying, and stabilizing properties. In meat industry, it is used for the production of low fat potatoes and sausages [22, 24, 25]. It is also used in tooth paste, fire-fighting foams, air fresheners, shampoos, and the cosmetic creams [26].

Carrageenan has shown various pharmaceutical properties including anticancer, anticoagulant, antihyperlipidemic, and immunomodulatory activities $[22,27]$. In vitro studies have revealed that CG may also have antiviral effects hindering the replication of hepatitis A virus [28]. In addition, other studies declared that CG effectively inhibits extensive range of sexually transmitted human papillomavirus [29]. Moreover, CG exhibits antioxidant activity also [30].

Because of its biocompatibility and consolidation behavior, CG is widely used by pharmaceutical scientists to improve drug formulation properties, especially to prolong drug release $[31,32]$. It also helps to create $\mathrm{pH} /$ temperature sensitive drug delivery systems. When CG is used as sole matrix material in order to control drug release, the desired drug release profiles such as zero-order release and $\mathrm{pH}$ independent release cannot be obtained [33].

Particularly, CG based formulations are used for prolonged drug release, that is, for many hours or days $[34,35]$. Some interesting features of CG like its adhesiveness and positive surface charge provide extra advantage in prolonging drug release in mucosal/epithelial tissues [36].

The interaction of CG with other polymers is used to attain ideal drug release profile. It has been studied that $\kappa-\mathrm{CG}$ showed fast release because of fast degeneration [37] or quick swelling $[31,32]$. The blending of different types of CG with each other also appears to be a good strategy to prolong drug release, although SEM studies showed that some CG are not miscible in blends [38]. The tablets formed by equal amount of $\iota$ - and $\lambda$-CG showed zero-order release profile of tripelennamine- $\mathrm{HCl}$. It can be explained as that $\lambda$-CG can encave the complexes of drugs and hydrated $\iota$-CG in viscous 


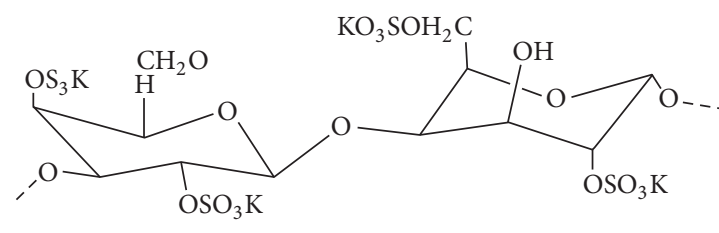

(a)

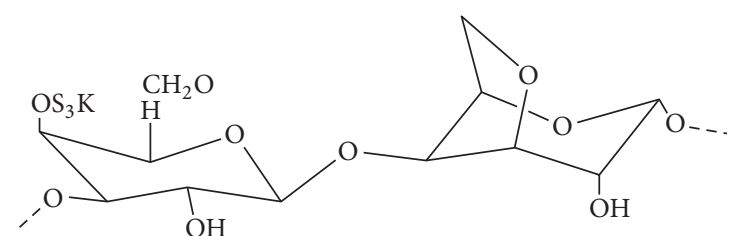

(b)

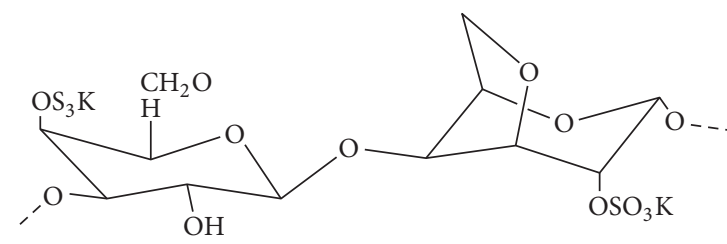

(c)

Figure 1: Structure of three types of carrageenan: (a) $\lambda$-CG, (b) $\kappa$-CG, and (c) $\iota$-CG.

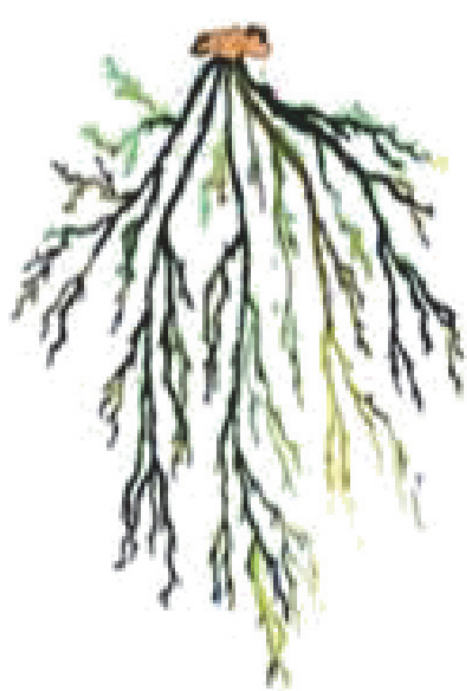

(a)

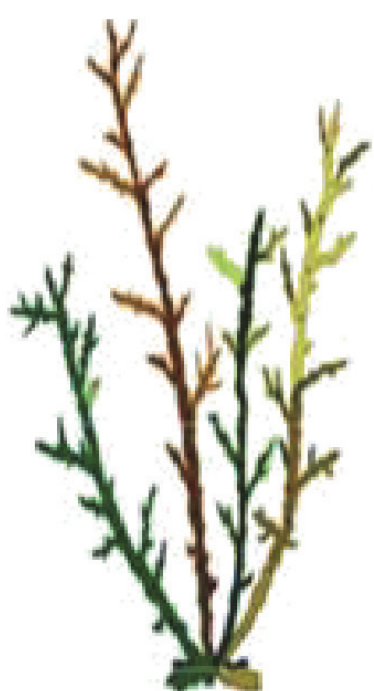

(b)

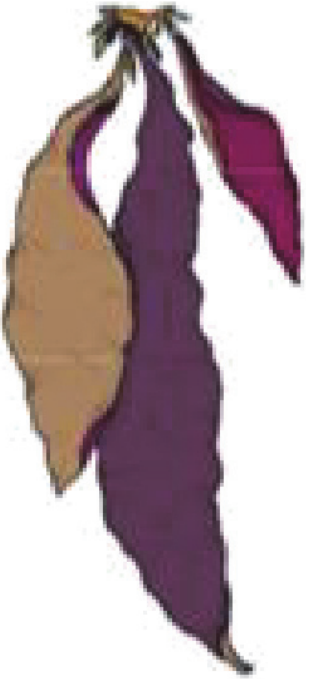

(c)

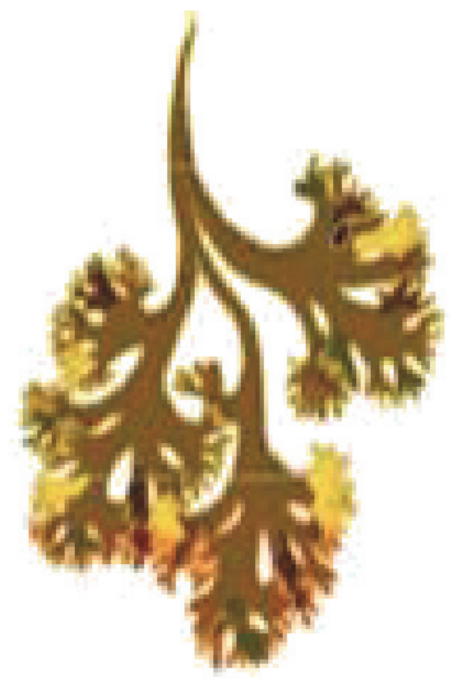

(d)

Figure 2: (a) Eucheuma denticulatum- (spinosum-) l-CG. (b) Kappaphycus alvarezii- (cottonii-) $\kappa$-CG. (c) Gigartina rodula- $\kappa$-/ $\lambda$-CG. (d) Chondrus crispus- $\kappa-/ \lambda$-CG.

shell of $\lambda$-CG [39]. This represents a smart "collaboration" between different types of CG in rational design of drug delivery system. The blending of CG with nanoparticles also enables prolonging drug delivery but different types of nanoparticles exhibit different effects. For example, the incorporation of gold nanofillers slows down the release rate of model drug (methylene blue: MB) [40]. In recent times, the applications of CG based formulations have extended to buccal [41], ophthalmic [42], and vaginal [43] drug delivery systems, as well as wide-ranging areas of wound healing [44] and tissue engineering [45].

In addition, $\kappa$-CG was also explored as the matrix of controlled release tablets. Using microcrystalline cellulose as the filler and theophylline monohydrate as model drug (20\%), the effect of $\kappa$-CG content on drug release was studied. It was observed that $20 \%(\mathrm{v} / \mathrm{v}) \kappa-\mathrm{CG}$ resulted in fast drug release. Slower release was observed at $30 \%(\mathrm{v} / \mathrm{v}) \kappa-\mathrm{CG}$ content while at $70 \%(\mathrm{v} / \mathrm{v}) \kappa$-CG, drug release followed zero-order kinetics [31, 32]. Other studies demonstrated that $\kappa$-CG can interact with chitosan in the presence of cross-linker tripolyphosphate (TPP) to form stable nanoparticles. The size of these nanoparticles and their positive surface charge is ideal for penetrating epithelial surface [46].

Water absorption capacity is another very simple and useful feature of CG polymers, which increases drug dissolution and thus increases the oral bioavailability of poorly watersoluble drugs [47]. Thus it can be used as a practical alternative to microcrystalline cellulose (MCC) pellet or gelatin capsule. In comparison to MCC pellets, the pellets fabricated with $\kappa$-CG enable water-insoluble drugs to collapse and then 
dissolve as quick as 20 min [47-49]. Taken together, the unique properties of all three CG varieties are now benefiting both oral and parenteral drug release in various ways.

1.1.2. Role of Iron Oxide Nanoparticles in Magnetically Guided and Magnetically Responsive Drug Delivery. Magnetic nanoparticles (MNPs) are one of the most commonly used nanoscale materials $[50,51]$. These are the core/shell type nanoparticle structures that consist of a magnetic core, which is encapsulated in an organic or polymeric coating. MNPs have hydrophobic surface with large surface-to-volume ratio, so they agglomerate in the absence of surface coating [52]. MNPs have unique magnetic phenomenon that is extremely different from their bulk counterparts. Since their properties can be employed in variety of applications, extending from storage media for magnetic memory devices to probes and vectors in biomedical sciences [53].

The large surface-to-volume ratio of magnetic nanoparticles provides abundant chemical active sites for biomolecule conjugation $[54,55]$. Their magnetic properties allow MNPs to be used in many applications related to drug and gene delivery, therapeutics and diagnostics. Besides their size, surface properties of MNPs are also very essential for their applications. Coating of MNPs with external layer of different materials provides an interesting approach for transforming their surface properties. Variety of coating materials are used to modify the surface chemistry of MNPs like organic polymers (dextran, chitosan, polyethylene glycol (PEG), polysorbate, and polyaniline), organic surfactants (sodium oleate and dodecylamine), inorganic materials (gold, silica, and carbon), and bioactive molecules (liposomes, peptides, and ligands/receptors). Coated nanoparticles have advantages over simple nanoparticles like they have less cytotoxicity, show increased dispersibility and biocompatibility, have better conjugation with other bioactive molecules, and have improved thermal and chemical stability [56, 57]. For in vivo studies, MNPs should have high magnetic saturation. For instance, nanoparticles with high magnetization are required as contrast agents for MRI. Mainly iron oxide nanoparticles are used for many applications. Iron oxide exists as magnetite $\left(\mathrm{Fe}_{3} \mathrm{O}_{4}\right)$ or maghemite $\left(\gamma-\mathrm{Fe}_{2} \mathrm{O}_{3}\right)$.

(1) Magnetically Guided Drug Targeting. Freeman et al. proposed the idea of magnetically guided drug targeting (MGDT). According to him, MNPs can be transported through vascular system to a particular point in the body with help of magnetic field (Figure 3). The method of MGDT involves the immobilization of drug in to MNPs under the effect of magnetic field gradient, followed by the injection of drug or drug carrier complex into the living body either via intravenous or intra-arterial injection, and finally, the use of high-gradient external magnetic fields generated by rareearth permanent magnets to guide the complex and concentrate it at the chosen target locations. Once the complex is concentrated at target in vivo, therapeutic agent is released from the magnetic carrier, either by enzymatic activity or via changes in physiological conditions such as $\mathrm{pH}$, osmolality, or temperature. This results in increased uptake of drug by

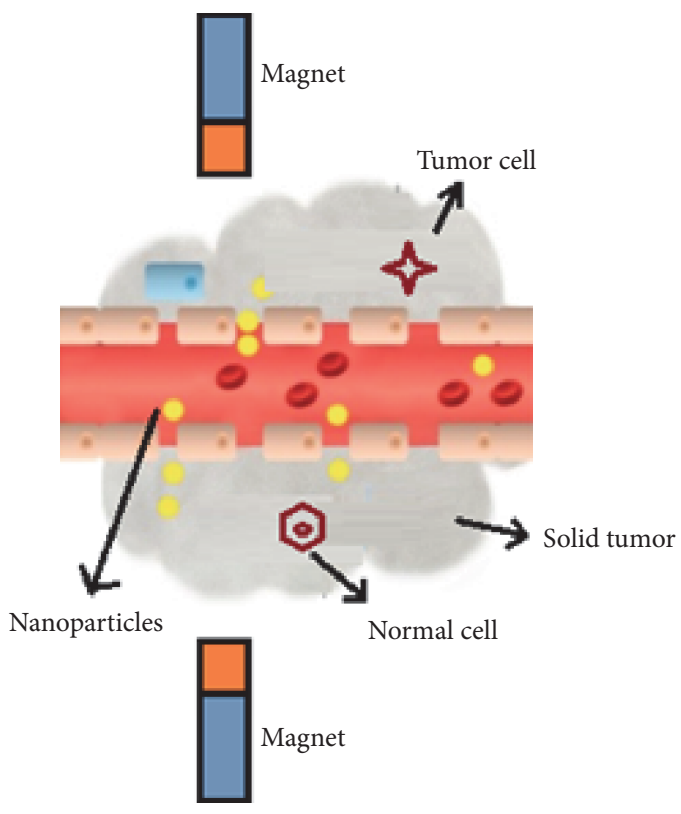

Figure 3: Magnetically guided drug targeting.

tumor cells at target sites [58] and a restricted systemic drug concentration [59].

The improvement in magnetically guided nanoparticles allows them to accumulate at particular pathologies such as inflammatory, tumors, and infectious sites. Those pathologies are characterized by structural abnormalities in the vasculature. This phenomenon is known as the enhanced permeability and retention (EPR) effect [60]. The method of MGDT depends not only on physical properties, concentrations, and the amount of particles applied but also on the type of binding of drugs. In addition, strength, geometry, and time interval of external magnetic field also affects MGDT. It also depends on the route of MNPs injection and the vascular supply to the targeted tissues.

(2) Magnetically Induced Drug Release. The idea of magnetically induced drug release (MIDR) was introduced by Kost et al. [61], who first used the idea of external magnetic field in order to achieve pulsatile release from polymer composites. He observed the insulin release from a magnetic composite of an ethylene-vinyl acetate copolymer by using low-frequency applied magnetic field (AMF). Even the inherent thermal energy from MNPs can also be used as an external and remote control trigger to control drug release. This energy opens up the gate for organic or inorganic carrier that contains drug for therapy. The first studies applied microwave radiation to liposomes with enwrapped ferromagnetic microparticles to stimulate drug release [62]. The applied magnetic field can suppress drug-drug carrier interactions and speed up diffusion [63]. In the presence of AMF, drug release rate is considerably enhanced, because the mechanical deformation of pulsatile system generates compressive and tensile stresses. Furthermore, AMF-triggered drug delivery systems use the collapse or volume transition of drug carriers to induce drug release [64]. 


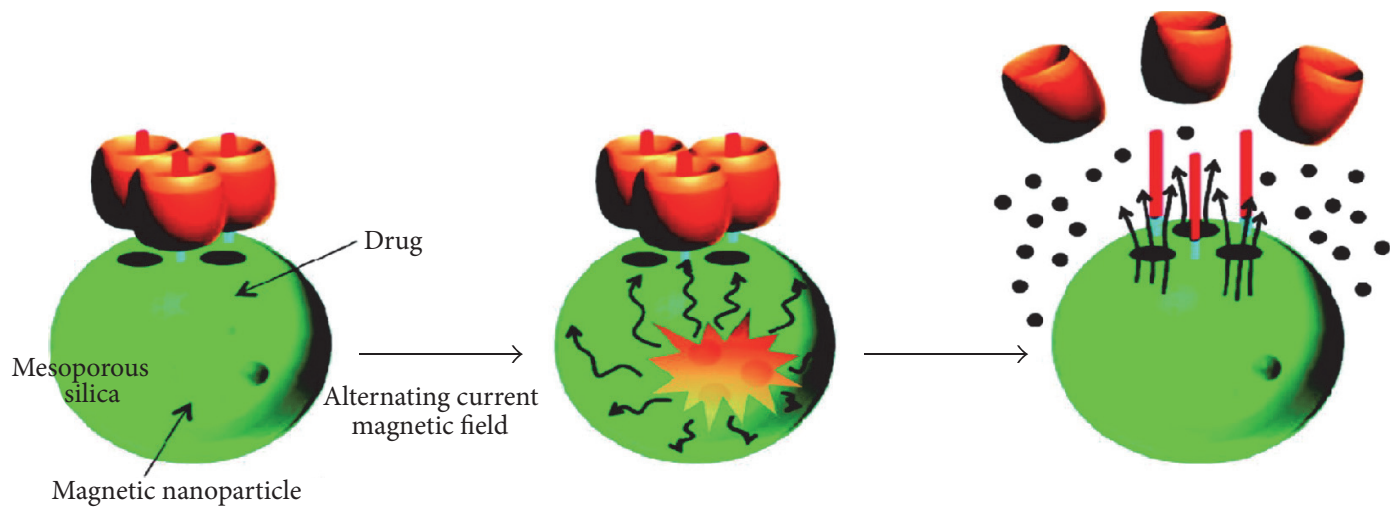

FIGURE 4: Magnetically triggered drug release system.

Liposomes provide a way of scattering and concentrating nanoparticles and drug through encapsulation or binding. The simple way to deliver drug from liposomes is diffusion through lipid bilayer. Diffusion is increased when the bilayer is phase separated or disrupted. Thus, the permeability of the bilayer affects the diffusion of drug, and the permeability of liposomes is highly increased around the membrane melting temperature (Tm), which rely on the lipid composition [65]. The cargo can be released if the liposome membrane is heated above Tm. Mechanistically, the heating intensity under high frequency magnetic field is controlled by the mode of magnetic energy decadence for single domain particles owing to two reasons: (i) external Brownian shifts and (ii) internal Neel fluctuations of the particle magnetic moment [66]. In order to use liposomes as thermoresponsive drug delivery vehicle, Tm is designed typically close to body temperature, to release the cargo at few degrees higher than the temperature of pathological tissue, such as cancer. Under such conditions, liposome leakage is produced during circulation to trigger cargo release under the effect of high frequency AMF. Magnetoliposomes were the first multifunctional hybrid liposome/nanoparticle assembly that received significant attention since 1988 [67].

Another approach for synthesis of polymeric MNPs includes the precipitation of MNPs within a porous polymer microparticles or nanoparticle scaffold [68]. One advantage of this technique is that particles with a relatively narrow size distribution can be produced, and well-defined spherical morphology can also be achieved (Figure 4). Specifically, $15 \mathrm{~nm}$ FONPs are inserted into the porous drug carrier with molecular valves [69]. A molecular valve, consisting of thread and capping molecule, blocks the silica pores to keep the drug inside. On applying an external AMF, the generation of heat and subsequent pressure buildup ( 90 bar) inside the porous nanoparticles causes the fast removal of molecular valves leading to release of the cargo. These materials are valuable for in vivo drug delivery such as release of doxorubicin (DOX) in breast cancer cells [69]. Hence, the development of MNPs and their use as drug carrier have attracted enormous attention. Major advantages of magnetofection include its simplicity, a modest cost, enhanced localization, efficient delivery, and drop in both incubation time and vector doses. The promising in vivo results have been reported for preclinical trials of gene transfection in cats for the treatment of feline fibrosarcomas. Meantime, magnetically sensitive MNPs establish a platform that shows the highest diversity in drug delivery field. Apart from the use of thermosensitive liposomes and gels that are sensitive to heat produced by the action of interchanging radiation on MNPs, other systems have produced encouraging results.

\section{Applications of Carrageenan Nanocomposites}

From the last few decades, scientists are putting their efforts to explore the applications of CG in biomedical field. Blending of nanoparticles (NPs) with CG enhances its properties and extends its use in pharmaceutical and biomedical applications. That is why use of CG based biomaterials is increasing (Table 1). So, there is a need to carefully analyze the properties of CG in order to use this type of polymer in broad range. Figure 5 presents various carrageenan nanocomposites reported in literature.

2.1. Nanocomposites Containing Carrageenan Only. Controlled drug delivery has attracted so much attention of pharmaceutical formulators. It is one of the greatest challenging therapeutic strategies for the treatment of chronic diseases. In this regard, biopolymers are proved very advantageous. In past few decades, CG based bionanocomposites have increasingly been used for pharmaceutical purposes. Carrageenan due to its gelling property improves the drug formulation and sustained release.

The interaction between filler components of nanocomposites at the nanometer scale enables them to act as molecular bridges in the polymer matrix: in fact it is the main reason for enhanced mechanical properties of the nanocomposite as compared to conventional microcomposites. Bionanocomposites add a new dimension to these enhanced properties due to the biocompatible and/or biodegradable nature of the material.

The incorporation of MNPs in polysaccharides is also being explored. Unique properties of ferrous oxide nanoparticles (FONPs) make nanocomposites a promising material for use in biomedical applications and form hydrogel 
TABLE 1: Important findings of previous studies involving carrageenan bionanocomposites.

\begin{tabular}{|c|c|c|c|c|}
\hline $\begin{array}{l}\text { Sr. } \\
\text { number }\end{array}$ & $\begin{array}{l}\text { Combination } \\
\text { polymer }\end{array}$ & Objective & Important findings & References \\
\hline (1) & $\kappa$-Carrageenan & $\begin{array}{l}\text { To examine the effect of FONPs on swelling, } \\
\text { kinetics, and drug release mechanism. }\end{array}$ & $\begin{array}{l}\text { Addition of MNPs causes high swelling ratio } \\
\text { and forms stronger gels. The release rate of } \\
\text { model drug can be tailored with the } \\
\text { concentration of MNPs. }\end{array}$ & {$[70]$} \\
\hline (2) & Poly vinyl alcohol & $\begin{array}{l}\text { To control the release of drug (diclofenac } \\
\text { sodium) via MNPs. }\end{array}$ & $\begin{array}{c}\text { Drug release depends on } \mathrm{pH} \text { and magnetic } \\
\text { field. }\end{array}$ & {$[71]$} \\
\hline (3) & $\begin{array}{l}\text { Carboxymethyl } \\
\text { chitosan }\end{array}$ & To modify drug release pattern. & $\begin{array}{l}\text { Increase in drug release by applying external } \\
\text { magnetic field as well as elevating of } \mathrm{pH}\end{array}$ & {$[72]$} \\
\hline (4) & Carrageenan & $\begin{array}{c}\text { To enhance the performance of carrageenan } \\
\text { hydrogels as drug delivery carrier in } \\
\text { gastrointestinal conditions. }\end{array}$ & Less release of methylene blue in stomach. & {$[40]$} \\
\hline (5) & $\kappa$-Carrageenan & $\begin{array}{l}\text { To develop new nanocomposite hydrogels via in } \\
\text { situ approach to find a suitable drug carrier for } \\
\text { GIT release. }\end{array}$ & $\begin{array}{l}\text { MB release increased with increased } \\
\text { concentration of NPs. }\end{array}$ & {$[73,74]$} \\
\hline (6) & Poly(acrylic acid) & $\begin{array}{c}\text { To produce novel biocompatible triple-response } \\
\text { hydrogels based on } k \text {-CG. }\end{array}$ & $\begin{array}{l}\text { Higher drug release in the absence of EMF at } \\
\qquad \mathrm{pH} 7 .\end{array}$ & {$[75]$} \\
\hline (7) & $\begin{array}{l}\text { Calcium carbonate } \\
\qquad\left(\mathrm{CaCO}_{3}\right)\end{array}$ & $\begin{array}{c}\text { To fabricate and characterize hybrid } \\
\text { microparticles (hNPs) to deliver doxorubicin } \\
\text { against cancer cells. }\end{array}$ & $\begin{array}{l}\text { Coupling of } \lambda \text {-CG to folic acid increased the } \\
\text { targeting of cancer cells. }\end{array}$ & {$[76]$} \\
\hline (8) & Chitosan & $\begin{array}{c}\text { To evaluate the release potential of natural } \\
\text { polymer coated MNPs for controlled release of } \\
\text { macromolecules. }\end{array}$ & Greater release of BSA at high $\mathrm{pH}$. & {$[77]$} \\
\hline (9) & None & $\begin{array}{l}\text { To explore the synergistic effect of } \iota-C G \text { and } \\
\text { MNPs in drug delivery and cancer therapy. }\end{array}$ & $\begin{array}{l}\text { Prepared nanocomposites proved to be } \\
\text { potential candidate for cancer therapy due to } \\
\text { apoptosis. }\end{array}$ & {$[78]$} \\
\hline (10) & None & $\begin{array}{l}\text { To explore the antibacterial applications of } \\
\text { inorganic biodegradable hydrogels. }\end{array}$ & $\begin{array}{c}\text { A strong zone of inhibition against Bacillus and } \\
\text { Escherichia coli. }\end{array}$ & {$[79]$} \\
\hline (11) & None & $\begin{array}{l}\text { To formulate environment-friendly } \\
\text { nanocomposite films comprising of carrageenan, } \\
\text { AgNPs, and clay mineral to investigate their } \\
\text { combined effect on antimicrobial activity and } \\
\text { physicochemical film properties. }\end{array}$ & $\begin{array}{c}\text { The combined use of both nanofillers (AgNPs } \\
\text { and clay) showed potential antimicrobial } \\
\text { activity against Gram-positive and } \\
\text { Gram-negative bacteria. }\end{array}$ & {$[80]$} \\
\hline (12) & None & $\begin{array}{c}\text { To synthesize CG/CNF nanocomposite films } \\
\text { and to study the effects of CNF concentrations } \\
\text { on various properties of CG/CNF } \\
\text { nanocomposite films. }\end{array}$ & $\begin{array}{l}\text { Strong antimicrobial activity of the prepared } \\
\text { films against Gram-positive food borne } \\
\text { pathogens (Listeria monocytogenes). }\end{array}$ & {$[81]$} \\
\hline (13) & None & $\begin{array}{l}\text { To enhance the physical barrier and mechanical } \\
\text { properties of CG based films by the addition of } \\
\text { nanoclay as well as to check the antimicrobial } \\
\text { effect of ZEO added in these films. }\end{array}$ & $\begin{array}{c}\text { Strong microbial activity against } S . \text { aureus, } B . \\
\text { cereus, E. coli, } S \text {. typhimurium, and } P . \\
\text { aeruginosa. }\end{array}$ & {$[82]$} \\
\hline (14) & $\begin{array}{l}\text { Carbon nanotubes } \\
\text { (CNTs) }\end{array}$ & $\begin{array}{c}\text { To prepare CG-based hydrogels impregnated } \\
\text { with CNTs and evaluate their swelling behavior } \\
\text { and adsorption performance of crystal violet } \\
\text { (CV) as model dye. }\end{array}$ & $\begin{array}{l}\text { Lower adsorption of CV at acidic pHs and high } \\
\text { adsorption at high pH. Moreover adsorption of } \\
\text { CV also increases with increase in } \\
\text { concentration of MCNT. }\end{array}$ & {$[83]$} \\
\hline
\end{tabular}

nanocomposites that are responsive to external magnetic field. An important advantage of these magnetic NPs is the magnetically driven transport of drug which allows site specific drug delivery [84]. Moreover by changing the external magnetic field, a remotely controlled release of encapsulated therapeutic agents can also be achieved $[85,86]$. Hence, such type of magnetic hydrogel nanocomposites is very efficient for the development of site specific or time controlled drug delivery systems $[87,88]$. In addition, MNPs also confer new functionalities to the resulting nanocomposites that are valuable for other biomedical applications like medical imaging $[89,90]$.

Impact of magnetic ferrous oxide on swelling behavior and release properties of $\mathrm{MB}$ has been studied by DanielDa-Silva and the companions. In this regard, $\kappa-C G$ based hydrogel nanocomposites have been synthesized. $\kappa$-CG was used as matrix and magnetic FONPs have been chosen as nanofiller and $\mathrm{MB}$ was used as model drug. It has been 


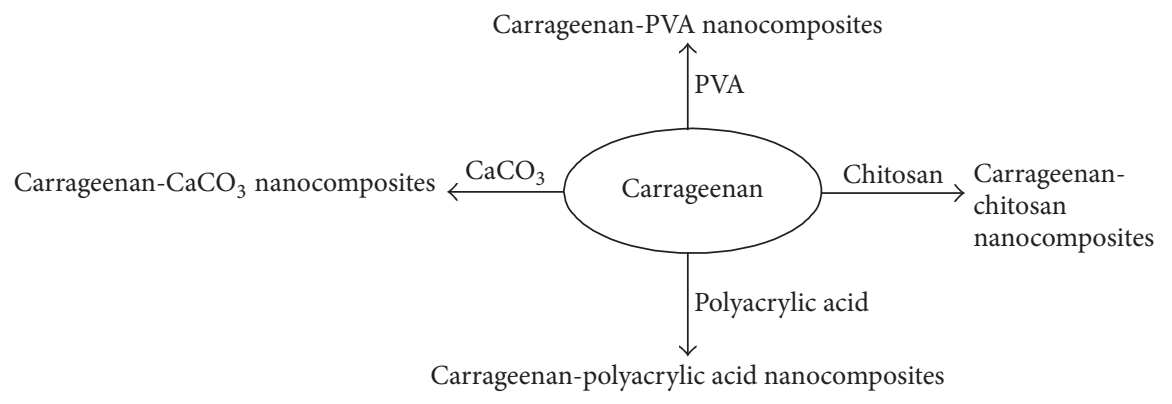

FIGURE 5: Carrageenan nanocomposites reported in literature.

noted that addition of MNPs and increase in its concentration causes increased swelling ratio and forms stronger gels, which affect oppositely the release rate of $\mathrm{MB}$. The release kinetics of MB depends upon the FONPs load. So, incorporation of nanoparticles to polyelectrolyte hydrogel is a valuable way to tailor the release rate of encapsulated drugs [70].

Raman et al. explained the synergistic effect of $\iota$-CG and MNPs in drug delivery. In this study, $\gamma$-FONPs were electrostatically entrapped in $\iota$-CG to develop a nanocomposite. The prepared nanocomposites were characterized by various analytical techniques and then in vitro analyses were made. These in vitro analyses reveal that the synthesized nanocomposites are potential candidate for cancer therapy due to apoptosis. This was confirmed by Hoechst 33342 and 7-AAD staining studies under fluorescent microscopy. MTT assay confirmed the biocompatibility of nanocomposites against normal cells. Cell apoptosis was induced by following the ROS-mediated mitochondrial pathway combined with downregulation of expression levels of mRNA of XIAP and PARP-1 and upregulation of caspase-3, Bcl-2, and Bcl-xL [78].

Moreover in 2015, other scientists like Shanmuga and his coworkers also prepared $\kappa$-CG loaded MNPs for the same purpose [91]. Other researchers also prepared $\kappa$-CG/gold (Au) nanocomposites and observed that spherical and rod shaped Au-NPs cause controlled diffusion of MB [40]. The incorporation of Au-NPs seems to slow down the rate of diffusion of MB molecules. This is probably due to the impact of the Au-NPs on the tortuosity of CG matrix. Tortuosity is a parameter that accounts for contribution of average pore size, distribution of pore size, and the pore interconnectivity of hydrogel which is inversely related to diffusion coefficient [92]. DSC confirmed that the incorporation of Au-NPs originates a more heterogeneous polymer network than in the original hydrogel. This causes changes in the tortuosity of CG matrix. An increases in tortuosity would cause smaller $\mathrm{MB}$ diffusion rate that could lead to a diffusion controlled mechanism [93, 94]. The anisotropy of gold nanofillers was found to affect the aggregation of CG helices, which render microstructures of hydrogel less homogeneous. For the equivalent content of $\mathrm{Au}-\mathrm{NPs}$, the release kinetics of $\mathrm{MB}$ depends on the nature of Au-NPs that are used as the dispersed phase. But MB release from CG hydrogels occurred through anomalous transport. It tended to be controlled by polymer relaxation and erosion, if spherical Au-NPs were incorporated. Considering that the addition of $\mathrm{Au}-\mathrm{NPs}$ originates stronger hydrogels, it would be expected that $\mathrm{MB}$ release followed a polymer relaxation mechanism irrespective of the shape of the Au-NPs [40].

Metal nanoparticles having high surface area have been extensively used because of their unique physiochemical properties including electronic properties, magnetic characteristics, antimicrobial activity, catalytic activity, and biomedical applications. These are also known to have bactericidal effects $[95,96]$.

Hence, Hezaveh and Muhamad investigated that addition of $\mathrm{MgO}$ nanoparticles in $\kappa$-CG hydrogel nanocomposites positively affects the release of $\mathrm{MB}$ in gastrointestinal tract (GIT). This concept is based on the fact that there are various substrates that could be known by anaerobic bacteria and are destroyed by enzymes in the colon [97]. So, it is valuable to fabricate polysaccharide based new materials that are stable in gastric environment and the colon targeted delivery. These NPs keep the loaded drug in their interphase with nanocomposite structure. When the nanocomposites are in contact with medium solution, these nanosized drug reservoirs release the entrapped $\mathrm{MB}$; hence it acts as drug releasing channels for $\mathrm{MB}$ within the hydrogel network. That is why drug release in nanocomposite hydrogels is higher than that of blank gels. It has been observed that less MB was released in stomach. This is due to the fact that, at low $\mathrm{pH}$, a compact network blocks the interphase region between the nanoparticles and the nanocomposite network [73, 74].

$\mathrm{He}$ also used silver and magnetic nanofillers in $\kappa$-CG nanocomposite hydrogels for the controlled release of $\mathrm{MB}$ in GIT. The nanocomposites containing silver (Ag) NPs showed profound $\mathrm{MB}$ release in acidic medium than intestinal medium while magnetite nanocomposite hydrogel exhibited better performance. High cumulative drug release of Ag-NPs loaded hydrogel can be accredited to the presence of AgNPs colloids with high surface charges in the network [73]. Moreover, increased concentration of NPs causes an increase in $\mathrm{MB}$ release and fine distribution of these NPs leads to more control over $\mathrm{MB}$ and causes smoother release. To increase the performance of nanocomposite hydrogels, the effect of natural cross-linking agent genipin was also investigated. Addition of cross-linker causes decreased MB release as it affects the porosity and structure of hydrogel network. Generally, cross-linking results in denser and more rigid hydrogel; 
the pore size decreases leading to the reduction in degree of swelling in aqueous medium. Cross-linking had a positive impact on drug release property and it has been seen that more targeted release was achieved due to genipin crosslinking $[73,74]$. Studies revealed that addition of genipin cross-linker also enhances the physical properties of polymer network which improves the controlled release property of nanocomposite hydrogel [97].

One of the most challenging subjects of research in food industry is to prepare environment friendly packaging material with additional antimicrobial properties for food safety and to increase its shelf life. Bionanocomposites with antimicrobial activity are most promising for this purpose [98-100]. The use of natural biopolymers for making biodegradable edible films has increased. Carrageenan has frequently been used for biodegradable packaging film preparation. To improve their properties, variety of nanofillers is used. Inorganic based biodegradable hydrogels are more capable for the inactivation of bacteria due to which they are mostly used in biomedical and biotechnological field [101].

Jayaramudu and his coworkers synthesized Ag-nanocomposite hydrogel with $\iota$-carrageenan through green process. Silver nanoparticles were prepared by reduction of silver nitrate $\left(\mathrm{AgNO}_{3}\right)$ in Azadirachta indica leaf extract in hydrogel network. These nanocomposite hydrogels were characterized by UV-Vis spectroscopy, X-ray diffraction spectroscopy, and other analytical techniques. The Ag-nanocomposite showed high swelling ratio because addition of Ag-ions led to the formation of NPs within the hydrogel system that expanded the gel networks and increased the water molecules uptake capacity. In addition, the antibacterial activity of biodegradable Ag-nanocomposite hydrogel was investigated against Bacillus and Escherichia coli. A strong zone of inhibition was seen against these species [79].

Another antimicrobial bionanocomposite film was synthesized by Rhim and Wang by using $\kappa$-CG, Ag-NPs, and organically modified nanoclay as a nanofiller. Addition of nanoclay increases the mechanical strength of these films. The films containing only Ag-NPs show strong antimicrobial activity against Gram negative bacteria [102]. The antibacterial action of Ag-NPs has not been established yet, but various mechanistic actions have been reported. First is the cell membrane disruption because of contact of Ag-NPs with sulfur and phosphorous containing compounds of DNA and proteins, which prevents DNA replication leading to cell death [103]. Second is the binding of the positive Ag-NPs with negatively charged bacterial cell membranes which disrupts the cell wall and surface proteins causing cell death [80]. Third is the penetration of Ag-NPs into the bacteria, which deactivates enzymes and yields $\mathrm{H}_{2} \mathrm{O}_{2}$ leading to cell death [104], while clay containing nanocomposites presented strong antibacterial activity against Gram-positive bacteria. The antimicrobial activity of clay is due to the presence of alkyl quaternary ammonium salt group in clay mineral. The synergistic effect of both nanofillers displayed potential antimicrobial activity against both Gram-positive and Gram negative bacterial strands [102].

Shankar et al. reported that chitin nanofibrils (CNF) reinforced $\kappa-\mathrm{CG}$ nanocomposites also show strong antimicrobial activity against Gram-positive food borne pathogens (Listeria monocytogenes). These films showed distinct antimicrobial activity against Listeria monocytogenes and seemed dependent on CNF concentration. The antibacterial activity of the $\mathrm{CNF}$ is probably due to the fact that it makes bacteria flocculate and inhibits growth through lack of nutrients and oxygen [81].

Later on, montmorillonite induced $\kappa$-CG films were developed by Shojaee-Aliabadi et al. using Zataria multiflora Boiss. essential oil, which acted as hydrophobic agent. The antimicrobial activity of prepared films was tested against five pathogens, that is, Staphylococcus aureus (S. aureus), Bacillus cereus, Escherichia coli, Salmonella typhimurium, and Pseudomonas aeruginosa through overlay and vapor phase process. Results showed that $\kappa$-CG/MMT (montmorillonite)/ZEO (Zataria multiflora essential oil) films showed strong antimicrobial activity against all pathogens. $\kappa$-CG/ nanoclay films did not show any inhibition against these tested bacteria [82]. Previous studies have also reported good inhibitory effect of ZEO against Salmonella typhimurium, Escherichia coli, Bacillus cereus, or Staphylococcus aureus [45, 46], but no information has been obtained about the activity of ZEO against Pseudomonas aeruginosa. The synergistic effect of both ZEO and nanoclay on antimicrobial, mechanical, and water vapor permeability properties was also noted [82].

Hosseinzadeh synthesized hydrogel nanocomposites using CG and multiwalled carbon nanotube (CNTs). These were prepared by in situ graft polymerization of acrylic acid in the presence of methylene bisacrylamide as cross-linker. The adsorption ability of hydrogel nanocomposite was inspected to remove crystal violet $(\mathrm{CV})$ as a cationic dye. It was seen that the adsorption capacity of nanocomposites varies with multiwalled carbon nanotube (MCNTs) concentration and agitation time as well as the $\mathrm{pH}$ of solution. The maximum adsorption capacity of CG/MCNTs hybrid hydrogel nanocomposite was found to be $118 \mathrm{mg} / \mathrm{g}$ [83].

\subsection{Nanocomposites Containing Carrageenan and PVA.} Moreover Mahdavinia and his coworker also investigated the influence of MNPs and $\kappa$-CG on swelling capacity and drug release property of interpenetrating polymer network (IPN) nanocomposite hydrogel composed of CG, polyvinyl alcohol, and FONPs. The produced polymer hydrogels loaded with diclofenac sodium (DS) were cross-linked by freezing thawing technique. The release study of DS revealed that drug release not only is $\mathrm{pH}$ dependent but also depends on magnetic field [72]. It was seen that amount of released drug was increased by increasing the strength of applied magnetic field. It has been suggested that, at low magnetic field, the magnetic moment of MNPs aligned together and led to the accumulation of FONPs. This aggregation of MNPs decreases the pore size of magnetic hydrogel which in turn decreases the diffusion of drug [105]. While at high applied magnetic field, larger diffusion of drug occurred. At different $\mathrm{pH}$, drug release was different due to difference in its solubility. Minimum drug release was observed at phosphate buffered saline (PBS) solution having $\mathrm{pH} 1.2$ because of low solubility 
of DS in acidic medium while maximum drug release was seen at $\mathrm{PBS}$ media with $\mathrm{pH}=7.4$.

It has also been proved that $\kappa$-CG based IPN nanocomposite hydrogels have the capability to inactivate the Grampositive $S$. aureus bacteria and the size of zone of inhibition was affected by the amount of drug in hydrogels [71].

\subsection{Nanocomposites Containing Carrageenan and Chitosan.} Furthermore, they had also reported dual natured magnetic and $\mathrm{pH}$ responsive hydrogel beads for controlled drug release. These hydrogel beads were derived from $\kappa$-CG/ carboxymethyl chitosan nanocomposites. FONPs were synthesized inside the polymers via in situ process. The prepared hydrogel beads showed maximum swelling at $\mathrm{pH}$ 7.4, while the addition of MNPs decreases it. The drug loading and release of DS showed that drug release is effected by $\mathrm{pH}$ and is increased by applying external magnetic field. At $\mathrm{pH} 1.2$, minimum drug release was seen. This is because of low solubility of DS at this $\mathrm{pH}$ which is due to the existence of weak carboxylic acid group on drug with $\mathrm{pKa}$ of 4 , while a large amount of drug release occurred at $\mathrm{pH} 7.4$ because the swelling of hydrogel beads increased significantly due to the neutralization of carboxylic acid groups on beads producing anionic carboxylate. The prepared beads showed magnetic properties. By applying external magnetic field, the amount of drug release varied. On applying external magnetic field, MNPs aligned with the AMF due to which the drug release increases. It occurs actually due to the continuous motion of MNPs. The fluctuation of AMF acts as stimulus to agitate the MNPs. The motion of MNPs increases which leads to relaxation of polymeric backbone causing an increased amount of released drug [106, 107]. Further increasing the strength of AMF, the amount of dug release also increases [72].

Long and his coworkers evaluated the potential of magnetic chitosan/CG nanocomposites for controlled release of macromolecules like protein. Magnetic CG nanocomposites were prepared at ambient conditions which were then incorporated into chitosan solution to gain CS/CRG nanocomposites. At the end, bovine serum albumin (BSA) was loaded. Due to the viscosity effect of CG, magnetic CG nanocomposites showed weak response to the AMF. That is why chitosan is used to prohibit cross-linking between the nearby chains of CG and to neutralize the charge of sulphate groups in particular surface. The loading capacity and release profile of the prepared nanocomposites demonstrated sustained release of protein in intestinal medium. About $85 \%$ of protein was released in 30 minutes. Moreover, at high $\mathrm{pH}$, a large amount of BSA was released because at high $\mathrm{pH}$, that is, 7, chitosan becomes insoluble due to which weak electrostatic interaction exists between chitosan and BSA. The zeta-potential of chitosan decreased with increase in $\mathrm{pH}$. Hence, the BSA was released at $\mathrm{pH} 7.4$, but not at $\mathrm{pH} 1.2$ or 6.8 [77].

2.4. Nanocomposites Containing Carrageenan and Polyacrylic Acid. Later on in 2013, K-CG-g-poly(acrylic acid)/SPION (superparamagnetic iron oxide nanoparticles) nanocomposite were prepared by Bardajee et al. for the controlled release of deferasirox. These nanocomposites were prepared by simultaneous development of SPION and the cross-linking of poly(acrylic acid) grafted onto the $\kappa$-CG $(\kappa \mathrm{C}$-g-PAA). The swelling property of obtained hydrogels was measured at different conditions. In vitro studies of $\kappa$-CG-PAA/SPION hydrogel studied were made at different temperature, $\mathrm{pH}$, and magnetic field. The rate of drug release was increased with increase in $\mathrm{pH}$ and temperature. While in the absence of external magnetic field (EMF) at $\mathrm{pH} 7$, higher drug amount was released as compared to that of in the presence of EMF. This is due to the formation of close configuration of hydrogel because of attractive forces between SPIONs and a quick decrease in the porosity volume of hydrogel. Thus, the drugs are strongly kept in the network of hydrogel, due to which diffusion of drug from the hydrogel is reduced. The biocompatibility studies also reveal that the prepared hydrogels are nontoxic and hence useful for biomedical applications [75].

\subsection{Nanocomposites Containing Carrageenan and Calcium} Carbonate. As biopolymers are proved very advantageous for the controlled delivery of drugs, Bosio and his coworkers developed calcium carbonate based hybrid nanoporous NPs. His objective was to develop hybrid NPs (hNPs) to deliver DOX to target cancer cells. The biopolymers used were derivatized with folic acid, since targeting of cancer cells is feasible by coupling $\lambda$-CG to folic acid in the microparticles (FA- $\lambda$-Car-hNPs). The specific surface area is also increased to ninefold. The anticancer activity of FA- $\lambda$-Car-hNPs was tested on human osteosarcoma MG-63 cells which indicated higher cytotoxicity and thus used as potential candidate for cancer therapy [76].

\section{Conclusion}

All the major three types of carrageenan and their nanocomposites provide diverse applications in pharmaceutical industry encompassing the delivery of small chemical drugs, proteins, and cells, as well as tissue regeneration using therapeutic biomacromolecule. The addition of nanoparticles in carrageenan composites enhances its pharmaceutical properties. The increasing information of structural analysis and chemical modifications of carrageenan allows the better utilization of carrageenan as probe to investigate various dangerous diseases, such as cancer and AIDS.

\section{Competing Interests}

The authors declare that they have no competing interests.

\section{Authors' Contributions}

Abida Kalsoom Khan and Ghulam Murtaza contributed equally. 


\section{References}

[1] S. L. Iconaru, A. M. Prodan, M. Motelica-Heino, S. Sizaret, and D. Predoi, "Synthesis and characterization of polysaccharidemaghemite composite nanoparticles and their antibacterial properties," Nanoscale Research Letters, vol. 7, pp. 1-8, 2012.

[2] K. Niemirowicz, K. H. Markiewicz, A. Z. Wilczewska, and H. Car, "Magnetic nanoparticles as new diagnostic tools in medicine," Advances in Medical Sciences, vol. 57, no. 2, pp. 196207, 2012.

[3] C. Lemarchand, R. Gref, and P. Couvreur, "Polysaccharidedecorated nanoparticles," European Journal of Pharmaceutics and Biopharmaceutics, vol. 58, no. 2, pp. 327-341, 2004.

[4] M. Muthiah, I.-K. Park, and C.-S. Cho, "Surface modification of iron oxide nanoparticles by biocompatible polymers for tissue imaging and targeting," Biotechnology Advances, vol. 31, no. 8, pp. 1224-1236, 2013.

[5] Y. A. Shchipunov, "Lecithin," in Encyclopedia of Surface and Colloid Science, pp. 2997-3017, Marcel Dekker, New York, NY, USA, 2002.

[6] E. Ruiz-Hitzky, M. Darder, and P. Aranda, "Functional biopolymer nanocomposites based on layered solids," Journal of Materials Chemistry, vol. 15, no. 35-36, pp. 3650-3662, 2005.

[7] V. Mittal, J. K. Kim, and K. Pal, Recent Advances in Elastomeric Nanocomposites, Springer, Berlin, Germany, 2011.

[8] M. Alexandre and P. Dubois, "Polymer-layered silicate nanocomposites: preparation, properties and uses of a new class of materials," Materials Science and Engineering R: Reports, vol. 28, no. 1, pp. 1-63, 2000.

[9] S. Letaief and C. Detellier, "Functionalized nanohybrid materials obtained from the interlayer grafting of aminoalcohols on kaolinite," Chemical Communications, no. 25, pp. 2613-2615, 2007.

[10] X. Li, W.-C. Chang, Y. J. Chao, R. Wang, and M. Chang, "Nanoscale structural and mechanical characterization of a natural nanocomposite material: the shell of red abalone," Nano Letters, vol. 4, no. 4, pp. 613-617, 2004.

[11] I. J. Colquhoun, A. J. Jay, J. Eagles et al., "Structure and conformation of a novel genetically engineered polysaccharide P2," Carbohydrate Research, vol. 330, no. 3, pp. 325-333, 2001.

[12] D. P. Cheney, A. H. Luistro, and P. M. Bradley, "Carrageenan analysis of tissue cultures and whole plants of Agardhiella subulata," in Twelfth International Seaweed Symposium: Proceedings of the Twelfth International Seaweed Symposium held in Sao Paulo, Brazil, July 27-August 1, 1986, vol. 41 of Developments in Hydrobiology, pp. 161-166, Springer, Berlin, Germany, 1987.

[13] Y. Chen, M.-L. Liao, and D. E. Dunstan, "The rheology of $\mathrm{K}^{+}-\kappa^{-}$ carrageenan as a weak gel," Carbohydrate Polymers, vol. 50, no. 2, pp. 109-116, 2002.

[14] F. Van De Velde, S. H. Knutsen, A. I. Usov, H. S. Rollema, and A. S. Cerezo, " ${ }^{1} \mathrm{H}$ and ${ }^{13} \mathrm{C}$ high resolution NMR spectroscopy of carrageenans: application in research and industry," Trends in Food Science and Technology, vol. 13, no. 3, pp. 73-92, 2002.

[15] N. Stanley, "Production, properties and uses of carrageenan. Production and utilization of products from commercial seaweeds," FAO Fisheries Technical Paper 288, FAO, Rome, Italy, 1987.

[16] M. E. Ensminger and A. H. Ensminger, Foods \& Nutrition Encyclopedia, Two Volume Set, CRC Press, 1993.

[17] D. J. McHugh, Production and Utilization of Products from Commercial Seaweeds, FAO, 1987.
[18] R. C. Rowe, P. J. Sheskey, M. E. Quinn, A. P. Association, and P. Press, Handbook of Pharmaceutical Excipients, Pharmaceutical Press, London, UK, 2009.

[19] N. S. Anderson, J. W. Campbell, M. M. Harding, D. A. Rees, and J. W. B. Samuel, "X-ray diffraction studies of polysaccharide sulphates: double helix models for $\kappa$ - and $l$-carrageenans," Journal of Molecular Biology, vol. 45, no. 1, pp. 85-97, 1969.

[20] R. Hoffmann, A. Russell, and M. Gidley, Molecular Weight Distribution of Carrageenans: Characterisation of Commercial Stabilisers and Effect of Cation Depletion on Depolymerisation, vol. 8 of Gums and Stabilisers for the Food Industry, IRL Press, 1996.

[21] H. Bixler, "The carrageenan connection IV," British Food Journal, vol. 96, no. 3, pp. 12-17, 1994.

[22] V. L. Campo, D. F. Kawano, D. B. D. Silva Jr., and I. Carvalho, "Carrageenans: biological properties, chemical modifications and structural analysis-a review," Carbohydrate Polymers, vol. 77, no. 2, pp. 167-180, 2009.

[23] S. H. Knutsen, S. T. Moe, B. Larsen, and H. Grasdalen, "Molecular cut-off values of dialysis membranes for alginate and $\kappa$-carrageenan oligosaccharides," in Proceedings of the 14th International Seaweed Symposium, Springer, Brest, France, 1993.

[24] H. M. Chen, X. J. Yan, F. Wang, W. F. Xu, and L. Zhang, "Assessment of the oxidative cellular toxicity of a $\kappa$-carrageenan oxidative degradation product towards Caco-2 cells," Food Research International, vol. 43, no. 10, pp. 2390-2401, 2010.

[25] K. Reddy, G. K. Mohan, S. Satla, and S. Gaikwad, "Natural polysaccharides: versatile excipients for controlled drug delivery systems," Asian Journal of Pharmaceutical Sciences, vol. 6, no. 6, pp. 275-286, 2011.

[26] J. Necas and L. Bartosikova, “Carrageenan: a review," Veterinarni Medicina, vol. 58, no. 4, pp. 187-205, 2013.

[27] I. Wijesekara, R. Pangestuti, and S.-K. Kim, "Biological activities and potential health benefits of sulfated polysaccharides derived from marine algae," Carbohydrate Polymers, vol. 84, no. 1, pp. 14-21, 2011.

[28] S. Girond, J. M. Crance, H. Van Cuyck-Gandre, J. Renaudet, and R. Deloince, "Antiviral activity of carrageenan on hepatitis A virus replication in cell culture," Research in Virology, vol. 142, no. 4, pp. 261-270, 1991.

[29] C. B. Buck, C. D. Thompson, J. N. Roberts, M. Müller, D. R. Lowy, and J. T. Schiller, "Carrageenan is a potent inhibitor of papillomavirus infection," PLoS Pathogens, vol. 2, no. 7, article e69, 2006.

[30] M. C. Rocha De Souza, C. T. Marques, C. M. Guerra Dore, F. R. Ferreira Da Silva, H. A. Oliveira Rocha, and E. L. Leite, "Antioxidant activities of sulfated polysaccharides from brown and red seaweeds," Journal of Applied Phycology, vol. 19, no. 2, pp. 153-160, 2007.

[31] K. M. Picker, "Matrix tablets of carrageenans. I. A compaction study," Drug Development and Industrial Pharmacy, vol. 25, no. 3, pp. 329-337, 1999.

[32] K. M. Picker, "Matrix tablets of carrageenans. II. Release behavior and effect of added cations," Drug Development and Industrial Pharmacy, vol. 25, no. 3, pp. 339-346, 1999.

[33] C. Maderuelo, A. Zarzuelo, and J. M. Lanao, "Critical factors in the release of drugs from sustained release hydrophilic matrices," Journal of Controlled Release, vol. 154, no. 1, pp. 2-19, 2011.

[34] A. Grenha, M. E. Gomes, M. Rodrigues et al., "Development of new chitosan/carrageenan nanoparticles for drug delivery 
applications," Journal of Biomedical Materials Research Part A, vol. 92, no. 4, pp. 1265-1272, 2010.

[35] M. Pavli, F. Vrečer, and S. Baumgartner, "Matrix tablets based on carrageenans with dual controlled release of doxazosin mesylate," International Journal of Pharmaceutics, vol. 400, no. 1-2, pp. 15-23, 2010.

[36] F. Kianfar, M. Antonijevic, B. Chowdhry, and J. S. Boateng, "Lyophilized wafers comprising carrageenan and pluronic acid for buccal drug delivery using model soluble and insoluble drugs," Colloids and Surfaces B: Biointerfaces, vol. 103, pp. 99106, 2013.

[37] D. Ghanam and P. Kleinebudde, "Suitability of $\kappa$-carrageenan pellets for the formulation of multiparticulate tablets with modified release," International Journal of Pharmaceutics, vol. 409, no. 1-2, pp. 9-18, 2011.

[38] S. Nanaki, E. Karavas, L. Kalantzi, and D. Bikiaris, "Miscibility study of carrageenan blends and evaluation of their effectiveness as sustained release carriers," Carbohydrate Polymers, vol. 79, no. 4, pp. 1157-1167, 2010.

[39] M. Hariharan, T. A. Wheatley, and J. C. Price, "Controlledrelease tablet matrices from carrageenans: compression and dissolution studies," Pharmaceutical Development and Technology, vol. 2, no. 4, pp. 383-393, 1997.

[40] A. M. Salgueiro, A. L. Daniel-Da-Silva, S. Fateixa, and T. Trindade, " $\kappa$-Carrageenan hydrogel nanocomposites with release behavior mediated by morphological distinct $\mathrm{Au}$ nanofillers," Carbohydrate Polymers, vol. 91, no. 1, pp. 100-109, 2013.

[41] K. Tomoda, M. Asahiyama, E. Ohtsuki et al., "Preparation and properties of carrageenan microspheres containing allopurinol and local anesthetic agents for the treatment of oral mucositis," Colloids and Surfaces B: Biointerfaces, vol. 71, no. 1, pp. 27-35, 2009.

[42] M. C. Bonferoni, P. Chetoni, P. Giunchedi et al., "Carrageenangelatin mucoadhesive systems for ion-exchange based ophthalmic delivery: in vitro and preliminary in vivo studies," European Journal of Pharmaceutics and Biopharmaceutics, vol. 57, no. 3, pp. 465-472, 2004.

[43] Y. Liu, Y.-Y. Zhu, G. Wei, and W.-Y. Lu, "Effect of carrageenan on poloxamer-based in situ gel for vaginal use: improved in vitro and in vivo sustained-release properties," European Journal of Pharmaceutical Sciences, vol. 37, no. 3-4, pp. 306-312, 2009.

[44] J. S. Boateng, H. V. Pawar, and J. Tetteh, "Polyox and carrageenan based composite film dressing containing antimicrobial and anti-inflammatory drugs for effective wound healing," International Journal of Pharmaceutics, vol. 441, no. 12, pp. 181-191, 2013.

[45] J. V. Araujo, N. Davidenko, M. Danner, R. E. Cameron, and S. M. Best, "Novel porous scaffolds of $\mathrm{pH}$ responsive chitosan/carrageenan-based polyelectrolyte complexes for tissue engineering," Journal of Biomedical Materials Research Part A, vol. 102, no. 12, pp. 4415-4426, 2014.

[46] S. Rodrigues, A. M. R. D. Costa, and A. Grenha, "Chitosan/carrageenan nanoparticles: effect of cross-linking with tripolyphosphate and charge ratios," Carbohydrate Polymers, vol. 89, no. 1, pp. 282-289, 2012.

[47] C. A. Peptu, L. Ochiuz, L. Alupei, C. Peptu, and M. Popa, "Carbohydrate based nanoparticles for drug delivery across biological barriers," Journal of Biomedical Nanotechnology, vol. 10, no. 9, pp. 2107-2148, 2014.

[48] M. Thommes and P. Kleinebudde, "Use of $\mathcal{\kappa}$-carrageenan as alternative pelletisation aid to microcrystalline cellulose in extrusion/spheronisation. II. Influence of drug and filler type," European Journal of Pharmaceutics and Biopharmaceutics, vol. 63, no. 1, pp. 68-75, 2006.

[49] H. Kranz, K. Jürgens, M. Pinier, and J. Siepmann, "Drug release from MCC- and carrageenan-based pellets: experiment and theory," European Journal of Pharmaceutics and Biopharmaceutics, vol. 73, no. 2, pp. 302-309, 2009.

[50] Y.-L. Su, J.-H. Fang, C.-Y. Liao, C.-T. Lin, Y.-T. Li, and S.-H. Hu, "Targeted mesoporous iron oxide nanoparticles-encapsulated perfluorohexane and a hydrophobic drug for deep tumor penetration and therapy," Theranostics, vol. 5, no. 11, pp. 12331248, 2015.

[51] J.-H. Fang, Y.-T. Lee, W.-H. Chiang, and S.-H. Hu, "Magnetoresponsive virus-mimetic nanocapsules with dual heattriggered sequential-infected multiple drug-delivery approach for combinatorial tumor therapy," Small, vol. 11, no. 20, pp. 24172428, 2015.

[52] A.-H. Lu, E. L. Salabas, and F. Schüth, "Magnetic nanoparticles: synthesis, protection, functionalization, and application," Angewandte Chemie-International Edition, vol. 46, no. 8, pp. 12221244, 2007.

[53] Y.-W. Jun, J.-W. Seo, and J. Cheon, "Nanoscaling laws of magnetic nanoparticles and their applicabilities in biomedical sciences," Accounts of Chemical Research, vol. 41, no. 2, pp. 179189, 2008.

[54] D. J. Craik, Magnetism: Principles and Applications, Wiley-VCH, 2003.

[55] C. Fang and M. Zhang, "Multifunctional magnetic nanoparticles for medical imaging applications," Journal of Materials Chemistry, vol. 19, no. 35, pp. 6258-6266, 2009.

[56] V. I. Shubayev, T. R. Pisanic II, and S. Jin, "Magnetic nanoparticles for theragnostics," Advanced Drug Delivery Reviews, vol. 61, no. 6, pp. 467-477, 2009.

[57] K. Chatterjee, S. Sarkar, K. J. Rao, and S. Paria, "Core/shell nanoparticles in biomedical applications," Advances in Colloid and Interface Science, vol. 209, pp. 8-39, 2014.

[58] J. Dobson, "Magnetic nanoparticles for drug delivery," Drug Development Research, vol. 67, no. 1, pp. 55-60, 2006.

[59] Z. Saiyed, S. Telang, and C. Ramchand, "Application of magnetic techniques in the field of drug discovery and biomedicine," BioMagnetic Research and Technology, vol. 1, no. 1, article 2, 2003.

[60] H. Maeda, J. Wu, T. Sawa, Y. Matsumura, and K. Hori, “Tumor vascular permeability and the EPR effect in macromolecular therapeutics: a review," Journal of Controlled Release, vol. 65, no. 1-2, pp. 271-284, 2000.

[61] J. Kost, J. Wolfrum, and R. Langer, "Magnetically enhanced insulin release in diabetic rats," Journal of Biomedical Materials Research, vol. 21, no. 12, pp. 1367-1373, 1987.

[62] M. Babincová, "Microwave induced likage of magnetoliposomes. Possible clinical implications," Bioelectrochemistry and Bioenergetics, vol. 32, no. 2, pp. 187-189, 1993.

[63] K. Hayashi, K. Ono, H. Suzuki et al., "High-frequency, magnetic-field-responsive drug release from magnetic nanoparticle/organic hybrid based on hyperthermic effect," ACS Applied Materials \& Interfaces, vol. 2, no. 7, pp. 1903-1911, 2010.

[64] T.-Y. Liu, K.-H. Liu, D.-M. Liu, S.-Y. Chen, and I.-W. Chen, "Temperature-sensitive nanocapsules for controlled drug release caused by magnetically triggered structural disruption," Advanced Functional Materials, vol. 19, no. 4, pp. 616-623, 2009. 
[65] M. B. Yatvin, J. N. Weinstein, W. H. Dennis, and R. Blumenthal, "Design of liposomes for enhanced local release of drugs by hyperthermia," Science, vol. 202, no. 4374, pp. 1290-1293, 1978.

[66] M. Lévy, C. Wilhelm, J.-M. Siaugue, O. Horner, J.-C. Bacri, and F. Gazeau, "Magnetically induced hyperthermia: sizedependent heating power of $\gamma-\mathrm{Fe}_{2} \mathrm{O}_{3}$ nanoparticles," Journal of Physics Condensed Matter, vol. 20, no. 20, Article ID 204133, 2008.

[67] M. L. Immordino, F. Dosio, and L. Cattel, "Stealth liposomes: review of the basic science, rationale, and clinical applications, existing and potential," International Journal of Nanomedicine, vol. 1, no. 3, pp. 297-309, 2006.

[68] M. L. Hans and A. M. Lowman, "Biodegradable nanoparticles for drug delivery and targeting," Current Opinion in Solid State and Materials Science, vol. 6, no. 4, pp. 319-327, 2002.

[69] C. R. Thomas, D. P. Ferris, J.-H. Lee et al., "Noninvasive remotecontrolled release of drug molecules in vitro using magnetic actuation of mechanized nanoparticles," Journal of the American Chemical Society, vol. 132, no. 31, pp. 10623-10625, 2010.

[70] A. L. Daniel-Da-Silva, J. Moreira, R. Neto, A. C. Estrada, A. M. Gil, and T. Trindade, "Impact of magnetic nanofillers in the swelling and release properties of $\kappa$-carrageenan hydrogel nanocomposites," Carbohydrate Polymers, vol. 87, no. 1, pp. 328$335,2012$.

[71] G. R. Mahdavinia and H. Etemadi, "In situ synthesis of magnetic CaraPVA IPN nanocomposite hydrogels and controlled drug release," Materials Science and Engineering C, vol. 45, pp. 250260, 2014.

[72] G. R. Mahdavinia, H. Etemadi, and F. Soleymani, "Magnetic/ $\mathrm{pH}$-responsive beads based on caboxymethyl chitosan and $\kappa$ carrageenan and controlled drug release," Carbohydrate Polymers, vol. 128, pp. 112-121, 2015.

[73] H. Hezaveh and I. I. Muhamad, "The effect of nanoparticles on gastrointestinal release from modified $\kappa$-carrageenan nanocomposite hydrogels," Carbohydrate Polymers, vol. 89, no. 1, pp. 138-145, 2012.

[74] H. Hezaveh and I. I. Muhamad, "Impact of metal oxide nanoparticles on oral release properties of $\mathrm{pH}$-sensitive hydrogel nanocomposites," International Journal of Biological Macromolecules, vol. 50, no. 5, pp. 1334-1340, 2012.

[75] G. R. Bardajee, Z. Hooshyar, and F. Rastgo, "Kappa carrageenang-poly (acrylic acid)/SPION nanocomposite as a novel stimulisensitive drug delivery system," Colloid and Polymer Science, vol. 291, no. 12, pp. 2791-2803, 2013.

[76] V. E. Bosio, M. L. Cacicedo, B. Calvignac et al., "Synthesis and characterization of $\mathrm{CaCO}_{3}$-biopolymer hybrid nanoporous microparticles for controlled release of doxorubicin," Colloids and Surfaces B: Biointerfaces, vol. 123, pp. 158-169, 2014.

[77] J. Long, X. Yu, E. Xu et al., "In situ synthesis of new magnetite chitosan/carrageenan nanocomposites by electrostatic interactions for protein delivery applications," Carbohydrate Polymers, vol. 131, pp. 98-107, 2015.

[78] M. Raman, V. M. Devi, and M. Doble, "Biocompatible $\iota$-carrageenan- $\gamma$-maghemite nanocomposite for biomedical applications-synthesis, characterization and in vitro anticancer efficacy," Journal of Nanobiotechnology, vol. 13, no. 1, p. 18, 2015.

[79] T. Jayaramudu, G. M. Raghavendra, K. Varaprasad, R. Sadiku, K. Ramam, and K. M. Raju, "Iota-Carrageenan-based biodegradable $\mathrm{Ag}^{0}$ nanocomposite hydrogels for the inactivation of bacteria," Carbohydrate Polymers, vol. 95, no. 1, pp. 188-194, 2013.
[80] Z. M. Sui, X. Chen, L. Y. Wang et al., "Capping effect of CTAB on positively charged Ag nanoparticles," Physica E: LowDimensional Systems and Nanostructures, vol. 33, no. 2, pp. 308314, 2006.

[81] S. Shankar, J. P. Reddy, J.-W. Rhim, and H.-Y. Kim, "Preparation, characterization, and antimicrobial activity of chitin nanofibrils reinforced carrageenan nanocomposite films," Carbohydrate Polymers, vol. 117, pp. 468-475, 2015.

[82] S. Shojaee-Aliabadi, M. A. Mohammadifar, H. Hosseini et al., "Characterization of nanobiocomposite kappa-carrageenan film with Zataria multiflora essential oil and nanoclay," International Journal of Biological Macromolecules, vol. 69, pp. 282-289, 2014.

[83] H. Hosseinzadeh, "Synthesis of carrageenan/multi-walled carbon nanotube hybrid hydrogel nanocomposite for adsorption of crystal violet from aqueous solution," Polish Journal of Chemical Technology, vol. 17, no. 2, pp. 70-76, 2015.

[84] B. Polyak and G. Friedman, "Magnetic targeting for site-specific drug delivery: applications and clinical potential," Expert Opinion on Drug Delivery, vol. 6, no. 1, pp. 53-70, 2009.

[85] M. Zrínyi, "Intelligent polymer gels controlled by magnetic fields," Colloid and Polymer Science, vol. 278, no. 2, pp. 98-103, 2000.

[86] T.-Y. Liu, S.-H. Hu, T.-Y. Liu, D.-M. Liu, and S.-Y. Chen, "Magnetic-sensitive behavior of intelligent ferrogels for controlled release of drug," Langmuir, vol. 22, no. 14, pp. 5974-5978, 2006.

[87] R. A. Frimpong and J. Z. Hilt, "Hydrogel nanocomposites for intelligent therapeutics," in Nanotechnology in Therapeutics: Current Technology and Applications, pp. 241-256, Horizon Press, Norwich, UK, 2007.

[88] N. S. Satarkar, D. Biswal, and J. Z. Hilt, "Hydrogel nanocomposites: a review of applications as remote controlled biomaterials," Soft Matter, vol. 6, no. 11, pp. 2364-2371, 2010.

[89] F. Shen, C. Poncet-Legrand, S. Somers et al., "Properties of a novel magnetized alginate for magnetic resonance imaging," Biotechnology and Bioengineering, vol. 83, no. 3, pp. 282-292, 2003.

[90] M. R. Saboktakin, R. Tabatabaie, A. Maharramov, and M. A. Ramazanov, "Synthesis and characterization of superparamagnetic chitosan-dextran sulfate hydrogels as nano carriers for colon-specific drug delivery," Carbohydrate Polymers, vol. 81, no. 2, pp. 372-376, 2010.

[91] S. Shanmuga, M. Singhal, and S. Sen, "Synthesis and characterization of carrageenan coated Ma," Translational Biomedicine, vol. 6, no. 3, 2015.

[92] A. S. Hoffman, "Hydrogels for biomedical applications," Advanced Drug Delivery Reviews, vol. 64, pp. 18-23, 2012.

[93] B. Walther, N. Lorén, M. Nydén, and A.-M. Hermansson, "Influence of $\kappa$-carrageenan gel structures on the diffusion of probe molecules determined by transmission electron microscopy and NMR diffusometry," Langmuir, vol. 22, no. 19, pp. 8221-8228, 2006.

[94] T. R. Thrimawithana, S. Young, and R. G. Alany, "Effect of cations on the microstructure and in vitro drug release of $\kappa$-and $\iota$-carrageenan liquid and semi-solid aqueous dispersions," Journal of Pharmacy and Pharmacology, vol. 63, no. 1, pp. 11-18, 2011.

[95] N. R. Nagireddy, M. M. Yallapu, V. Kokkarachedu et al., "Preparation and characterization of magnetic nanoparticles embedded in hydrogels for protein purification and metal 
extraction," Journal of Polymer Research, vol. 18, no. 6, pp. 22852294, 2011.

[96] H. Hezaveh, I. I. Muhamad, I. Noshadi, L. Shu Fen, and N. Ngadi, "Swelling behaviour and controlled drug release from cross-linked $\kappa$-carrageenan/NaCMC hydrogel by diffusion mechanism," Journal of Microencapsulation, vol. 29, no. 4, pp. 368-379, 2012.

[97] H. Hezaveh and I. I. Muhamad, "Modification and swelling kinetic study of kappa-carrageenan-based hydrogel for controlled release study," Journal of the Taiwan Institute of Chemical Engineers, vol. 44, no. 2, pp. 182-191, 2013.

[98] H. M. C. De Azeredo, "Nanocomposites for food packaging applications," Food Research International, vol. 42, no. 9, pp. 1240-1253, 2009.

[99] T. V. Duncan, "Applications of nanotechnology in food packaging and food safety: Barrier materials, antimicrobials and sensors," Journal of Colloid and Interface Science, vol. 363, no. 1, pp. 1-24, 2011.

[100] C. Silvestre, D. Duraccio, and S. Cimmino, "Food packaging based on polymer nanomaterials," Progress in Polymer Science, vol. 36, no. 12, pp. 1766-1782, 2011.

[101] K. Malachová, P. Praus, Z. Pavlíčková, and M. Turicová, “Activity of antibacterial compounds immobilised on montmorillonite," Applied Clay Science, vol. 43, no. 3-4, pp. 364-368, 2009.

[102] J.-W. Rhim and L.-F. Wang, "Preparation and characterization of carrageenan-based nanocomposite films reinforced with clay mineral and silver nanoparticles," Applied Clay Science, vol. 9798, pp. 174-181, 2014.

[103] J. R. Morones, J. L. Elechiguerra, A. Camacho et al., "The bactericidal effect of silver nanoparticles," Nanotechnology, vol. 16, no. 10, p. 2346, 2005.

[104] M. Raffi, F. Hussain, T. M. Bhatti, J. I. Akhter, A. Hameed, and M. M. Hasan, "Antibacterial characterization of silver nanoparticles against E. coli ATCC-15224," Journal of Materials Science and Technology, vol. 24, no. 2, pp. 192-196, 2008.

[105] J. Choubey and A. K. Bajpai, "Investigation on magnetically controlled delivery of doxorubicin from superparamagnetic nanocarriers of gelatin crosslinked with genipin," Journal of Materials Science: Materials in Medicine, vol. 21, no. 5, pp. 15731586, 2010.

[106] S.-H. Hu, T.-Y. Liu, H.-Y. Huang, D.-M. Liu, and S.-Y. Chen, "Magnetic-sensitive silica nanospheres for controlled drug release," Langmuir, vol. 24, no. 1, pp. 239-244, 2008.

[107] R. Gupta and A. K. Bajpai, "Magnetically guided release of ciprofloxacin from superparamagnetic polymer nanocomposites," Journal of Biomaterials Science, Polymer Edition, vol. 22, no. 7, pp. 893-918, 2011. 


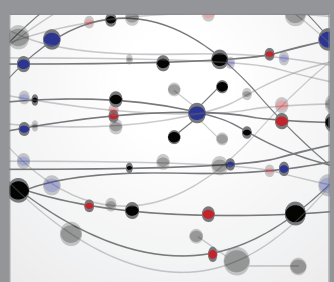

The Scientific World Journal
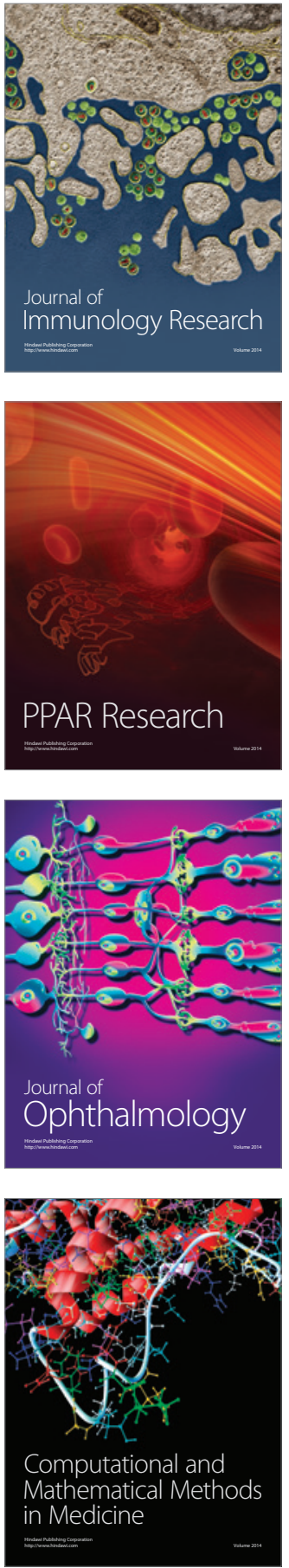

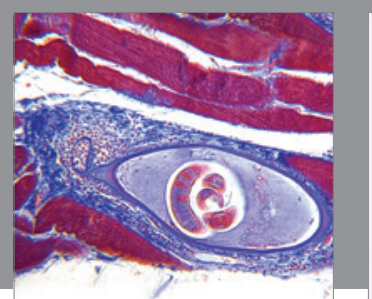

Gastroenterology Research and Practice
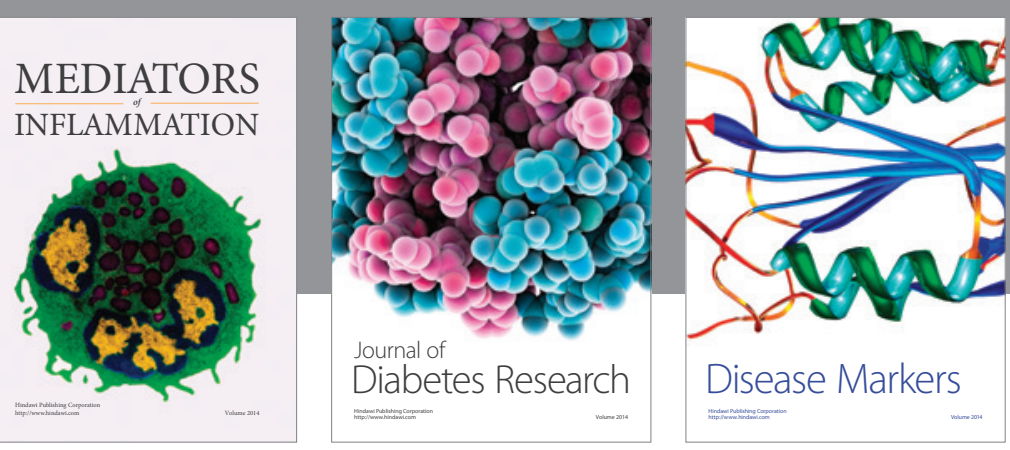

Disease Markers

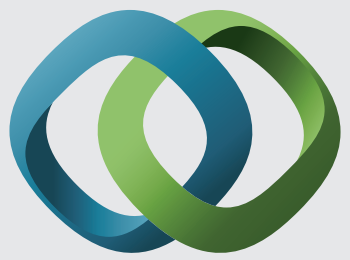

\section{Hindawi}

Submit your manuscripts at

https://www.hindawi.com
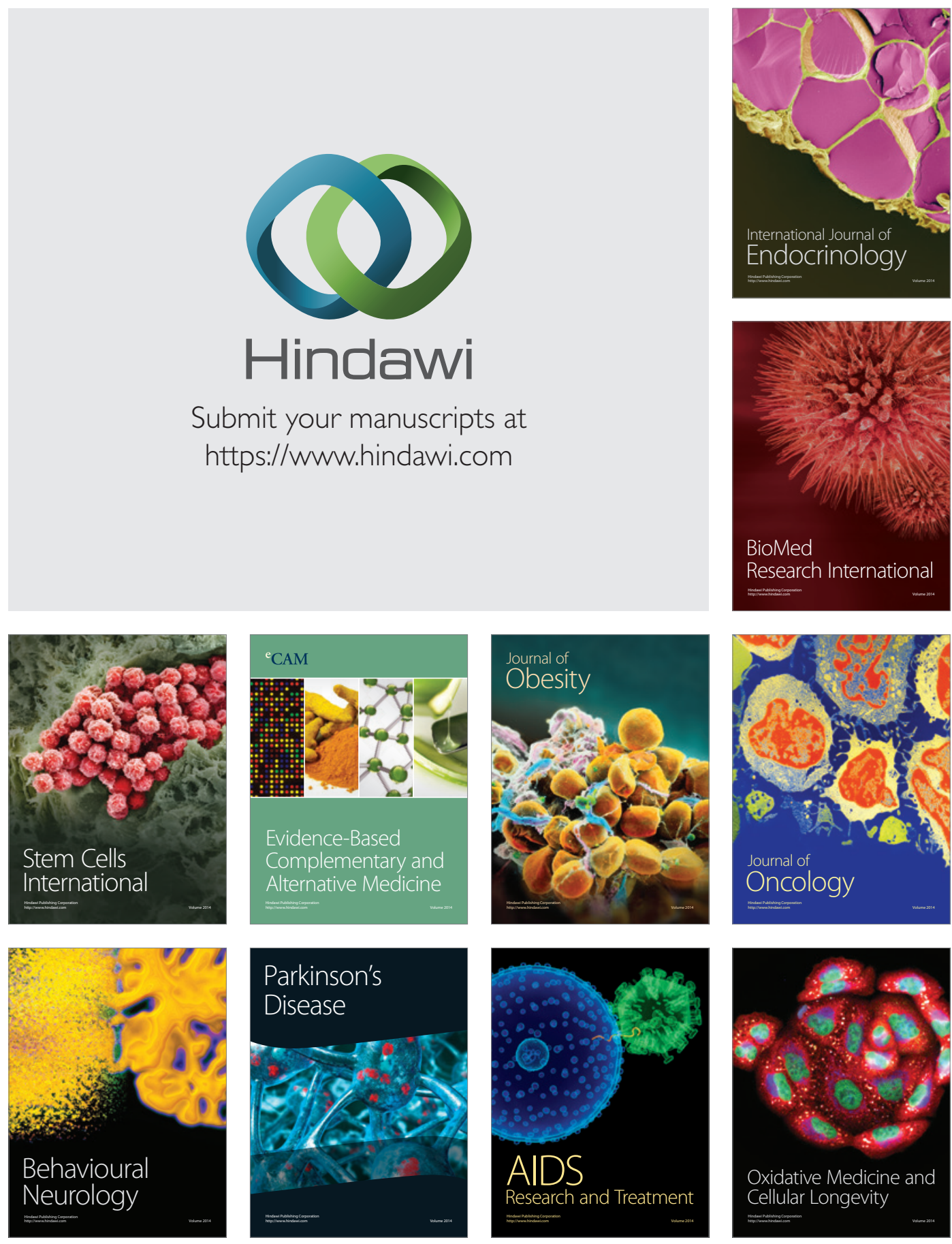